\title{
The importance of a participatory approach to resolving issues of sustainable agriculture
}

T.G. PARMINTER, M.E. WEDDERBURN, and P.J. SPIJKERBOSCH AgResearch, Whatawhata Research Centre, Private Bag 3089. Hamilton

\begin{abstract}
A participatory study with Waikato livestock farmers identified that lack of information to implement sustainability objectives is limiting the ability of some farmers to improve the condition of their natural resources.
\end{abstract}

Keywords: evaluative matrix, information, resource management, sustainable agriculture

\section{Introduction}

Farmers have always had to make management decisions affecting the natural resources on their properties. Many make their decisions in relative isolation from other people in their community and with a high degree of autonomy (Parminter 1994). Increased community awareness and their ability to influence land-owner activities through the Resource Management Act 1991 has resulted in closer inspection by a range of interest groups of current farm practices and their effect upon natural resources (Pinnell 1993). Other agencies in agricultural export markets also need assurance that New Zealand farmers are managing their farms' sustainably (New Zealand Wool Board 1992; New Zealand Meat Producers' Board 1993). Farming groups responding to community and market signals have sought a partnership approach to understanding and improving agriculture's impact upon the environment. A participatory research programme that includes farmer collaboration and meets their socio-economic needs is the best way of achieving long-term benefits from investment in agricultural research (World Bank 1991). Participatory research in sustainable agriculture highlights farmers' resource needs, and how these can be managed sustainably by farmers to benefit all communities.

\section{Method}

This study was designed to prioritise farmer information needs to achieve a range of farming goals. It is based upon farmer-derived goals, objectives, and managements for sustainable agriculture (Cotman 1996). As part of this process a group of 15 scientists and 15 farmers who had recent experience in agricultural policy and sustainable farm management, attended a workshop reviewing farmer goals and their associated management objectives. Workshop participants were asked to prioritise farmers' management objectives and identify potential shortfalls in information to implement them successfully.

An evaluative matrix was used to measure how well each management objective was perceived by participants to fulfil specific criteria (Chambers 1988; Mascarenhas et al. 199 1). Each row of the matrix had a different management objective, and each column a different criteria, e.g., resource management, annual profitability, and satisfying lifestyle, (farming goals obtained from previous workshops) with which the objectives were evaluated. The strength of the association between management objective and criteria was specified by each respondent on a $0-20$ scale, with 20 signifying the greatest strength.

To establish management priorities, respondents were asked to score how important each management objective was to achieving farmer goals. Farmers were then asked about the availability of information to optimise the application of each management objective, and this was scored on a second matrix. Scientists were asked about the quantity of information to optimise the application of each farming objective.

\section{Results}

\section{Management objective priorities}

Farmers had different degrees of importance for management practices depending upon the goal being pursued. Their scores have been converted into a ranking to make the priority objectives more visible, and are shown in Table 1.

Farmers ranked "protection of stream banks", "setting seasonal stocking rates" and obtaining the best "balance of livestock classes for grazing" highly for achieving their resource management goals. Of these, only the "setting of seasonal stocking rates" also scored highly on the other goal areas, as shown by its average score ranking first. "Protection of stream banks" was the highest ranked objective for resource management, but its average score was ranked low because it was not consistent with achieving annual profitability or a satisfying lifestyle. 
Scientists had some different resource management priorities compared to farmers, but "protection of stream banks", "setting seasonal stocking rates", and obtaining the best "balance of livestock classes for grazing" were still ranked highly at 5, 6 and 10 respectively. For farmers to achieve their natural resource management goals, scientists ranked "selecting suitable livestock enterprises" as the highest priority management objective.

\section{Information and sustainability goals} Farmers' scores for the availability of information to optimise resource management goals are shown in Figure 1. Farmers identified "grazing mob densities", "seasonal" and "annual stocking rates", and "use of veterinary remedies", as being objectives which had the least available information. Farmers' perceptions of the most available information on resource management was the "use of animal shelter", "stock health and condition", and "protection of stream banks and waterways".

Scientists' scores for the quantity of information provided to farmers for them to optimise their resource management goals are shown in Figure 2. All scientists' results have been adjusted to the same overall mean as the farmers' scores for comparison. Scientists scored the lowest for "sound use of veterinary remedies", "seasonal stocking rates", "targets for stock performance", and "feed allocation priorities", indicating that these objectives had the least amount of information.

For scientists, objectives involving "suitable animal breeds", "animal genetic improvement", and "plant genetic improvement" have the most amount of information for farmers to optimise their resource management goals.

Different farming goals have different information needs, as shown by comparing Figures 3 and 4 with Figures 1 and 2. Overall the scores for objectives in relation to resource management goals were lower than those for cash profitability. The difference was perceived to be greater from scientists' perspectives than from farmers'.

\section{Information and profitability goals}

Farmers' scores for the availability of information to optimise profitability goals are shown in Figure 3. Farmers identified "use of animal shelter", "protection of stream banks", and setting "grazing mob densities" as being objectives for which the least amount of information was available. Even here, their scores were still greater than any scores for sustainability information. The most available information to farmers was "stock health and condition", "pasture quality", and "pasture utilisation".

The scientists' adjusted scores for the quantity of information provided for farmers to optimise their profitability goals are shown in Figure 4. Scientists' results were similar to those of farmers. Scientists perceived there to be the most information about "suitable livestock enterprises", "suitable animal breeds", and "stock health and condition". Almost all the scientists' scores for information and profitability were above those for information and sustainability except for "use of animal shelter" and "protection of stream banks".

\section{Information and lifestyle goals}

The quantity and availability of information to optimise lifestyle goals was also obtained from respondents. Rcsults were generally intermediate between those for resource management and profitability goals.

\section{Discussion}

Previous studies have shown farmers wanted sustainability issues to be considered in terms of their effects upon farm profitability, and farming lifestyles, as well as resource management (Parminter et al. 1994). When farmers' priorities for sustainability objectives in relation to each goal area are compared (Table 1) there is a potential conflict between the priority of some 
Figure 1

Farmers' matrix scores for the information available about each management objective to optimise on-farm natural resource decisions. Twenty represents high availability.

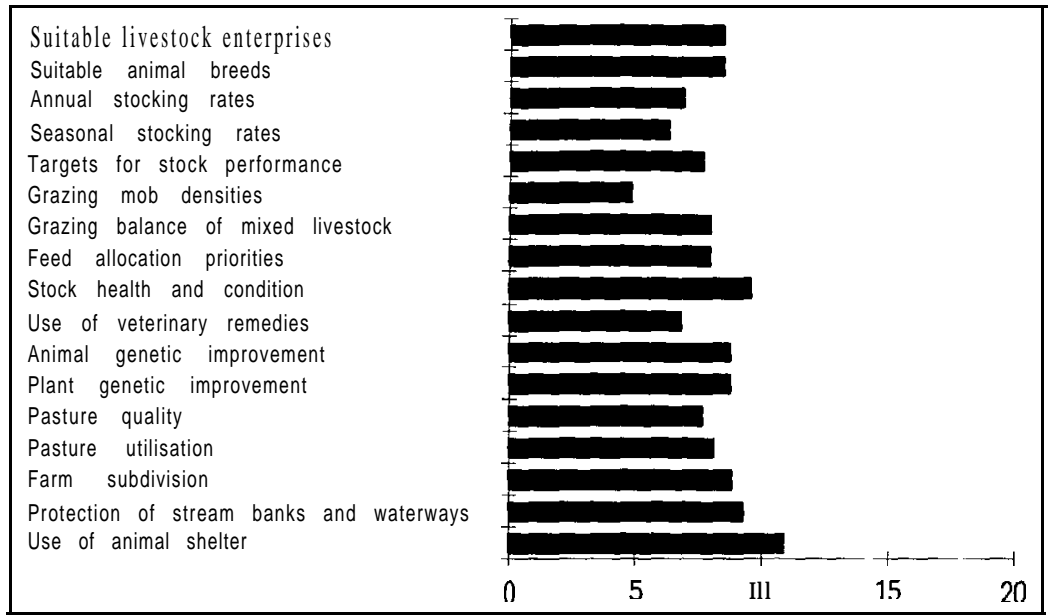

Suitable livestock enterprises
Suitable animal breeds
Annual stocking rates
Seasonal stocking rates
Targets for stock performance
Grazing mob densities
Grazing balance of mixed livestock
Feed allocation priorities
Stock health and condition
Use of veterinary remedies
Animal genetic improvement
Plant genetic improvement
Pasture quality
Pasture utilisation
Farm subdivision
Protection of stream banks and waterways
Use of animal shelter

Figure 2

Scientists' matrix scores for the quantity of information able to be accessed about each management objective to optimise on-farm natural resource decisions. Twenty represents a high quantity. objectives for sustainability and their priority for achieving profitability or satisfactory lifestyles. Management objectives may be difficult to promote for their effect upon resource condition if they do not also support profitability and lifestyle goals.

Although many farmers know that resource condition is an important social issue, where there is a lack of consistent benefits across a range of farming goals, management objectives highly ranked for improving resource condition are unlikely to be rapidly adopted. Some policy agencies are promoting riparian strips for stream bank protection on the basis that they will improve water quality. This study would indicate that this benefit is already widely acknowledged by livestock farmers. The challenge to the policy agencies is to have the information to promote the benefits of riparian strips upon farm profitability, and farming lifestyles, so that riparian strips have an overall higher ranking across all farming goals.

Initial steps to implement the Resource Management Act 199 \& by policy agencies should be to promote those management objectives that are already perceived to be consistent overall with goals for resource condition, profitability, and lifestyle. Some examples ofobjectives that ranked moderately well for improving resource condition in Table 1, but were ranked highly overall the goals, include "setting seasonal stockingrates", "selecting suitable livestock enterprises", and "grazing a balance of mixed livestock". For instance, a high proportion of farmers may be prepared to revise their decisions on seasonal stocking rates to reduce the effect of the farm upon water catchment sedimentation. Such changes may be more effective across a whole catchment than one or two percent of farmers putting in riparian strips. 


\section{Figure 3}

Farmers' matrix scores for the information available about each management objective to optimise farm profitability. Twenty represents high availability.
Figure 4

Scientists' matrix scores for the quantity of information able to be accessed about each management objective to optimise on-farm profitability. Twenty represents a high quantity.

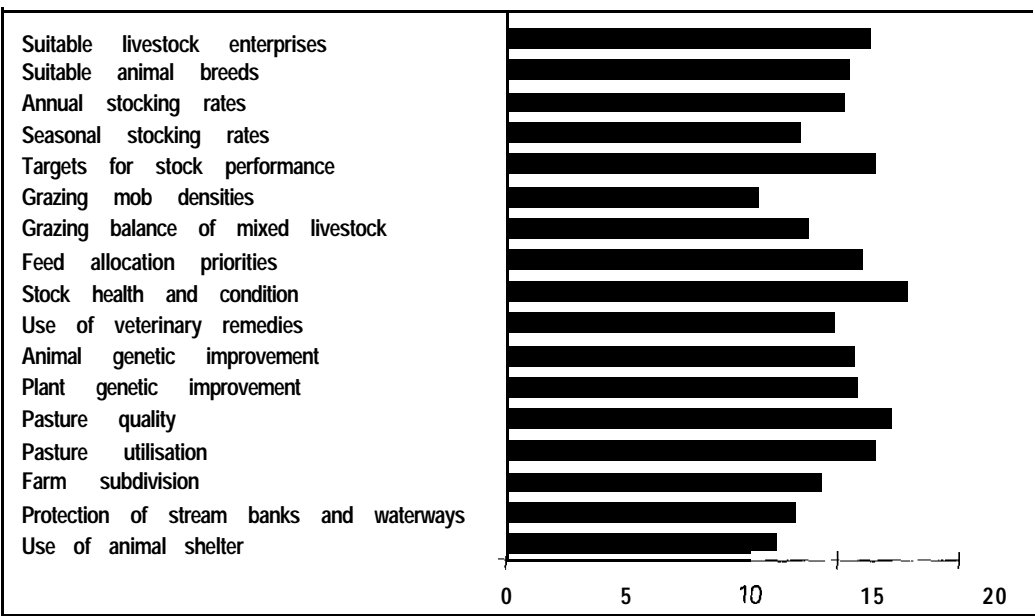

Suitable livestock enterprises
Suitable animal breeds
Annual stocking rates
Seasonal stocking rates
Targets for stock performance
Grazing mob densities
Grazing balance of mixed livestock
Feed allocation priorities
Stock health and condition
Use of veterinary remedies
Animal genetic improvement
Plant genetic improvement
Pasture quality
Pasture utilisation
Farm subdivision
Protection of stream bank and waterways
Use of animal shelter

For many of the more highly ranked objectives for achieving resource management goals there was perceived to be a low level of adequate information for them to be implemented in an optimal manner. Farmers perceived some management objectives had more information available to them than scientists indicated in their results. This particularly applies to "use of animal shelter" and "protection of stream banks and waterways". This difference may reflect farmers' use of information that is not scientifically derived, or a lack of confidence by scientists in the quality of information that farmers are using.

Scientists perceived there to be more information about many management objectives and optimising profitability than most of the farmers perceived there to be available. For instance, selecting "suitable animal breeds", "livestock enterprises", and "annual stocking rates" all had less information available to farmers than scientists perceived should be the case. Farmers' lower scores may indicate that the information available to them is inadequate to assist in their decision making, or it is possible that some of the science information that has been produced has not yet reached the farming community.

In particular, this study has highlighted that there is a lack of information for farming decision makers about the effects of management objectives upon resource condition. It has also shown that for management objectives of high priority for improving resource condition, there is a lack of information about their effect upon other farming goals such as farm profitability.

Farmers are attempting to optimise a management strategy across all three goals in study groups. They meet regularly to include natural resource management 
issues in their productive farming strategies and decisions. The study groups aim to "pool" farmers' collective experience and the research knowledge of scientists. In this way farmers hope to overcome some of the information gaps that presently exist, and so improve their ability to implement management practices that can improve the condition of their natural resources, as part of improving the sustainability of farming. Scientists are looking at ways to implement management practices and identify future research needs.

The use of a participatory process has enabled the identification of components and interactions in agricultural systems as they are perceived by their decision makers. This participatory study has been able to combine the benefits of farmers' and scientists' knowledge so that its results have been relevant and useful to the end users and have been accepted with confidence by farmers and scientists. Both of these aspects are important to resolve sustainable agriculture issues.

\section{ACKNOWLEDGMENTS}

Our thanks go to the many farmers, scientists, and policy agencies who contributed to this study. We also appreciated the funding from $\mathrm{AgResearch}$ that enabled it to be carried out.

\section{REFERENCES}

Chambers, R. 1988. After the Green Revolution: Sustainable Agriculture for Development. Earthscan Publications Ltd, London.

Cotman, G.H. 1996. Farmer Perspectives on Sustainable Farming. Proceedings of the New Zealand Grassland Association 57. In press.
Mascarenhas, J. et al. 1991. PRA in India: Review and Future Directions in Participatory Rural Appraisal: Proceedings of the February 1991 Bangalove PRA Trainers Workshop. RRA Notes Number 13, August 199 1. International Institute for Environmeñt and Development, London.

Moss, G. 1991. The Trainers Handbook. Moss Associates Ltd, NZ.

New Zealand Meat Producers Board 1993. Strategic Plan 1993-2000. New Zealand Meat Producers Board Public Document, p. 20.

New Zealand Wool Board 1992. Strategic Directions for the New Zealand Wool Industry 1992-2000. NZ Wool Board Public Document, p. 4.

Parminter, T.G.; Wedderburn, M.E.; Carter, J.C. 1993. Waikato Regional Workshops on Sustainable Agriculture: A Partnership Approach by Federated Farmers, AgResearch, and Environment Waikato. AgResearch Public Document.

Parminter, T.G. 1994. Interim Report for Adoption Research of Beef Breeding Technologies; Stage 2. New Zealand Meat Research and Development Council Report.

Parminter, T.G.; Wedderbum, M.E.; Carter, J.C.; Paine, M.S. 1994. Attitudes and Beliefs of Waikato Farmers to Sustainable Agriculture. 1994 New Zealand Conference on Sustainable Land Management, Lincoln University.

Pinnell, G. 1993. New Rules on Land Control Go 'Too Far'. Waikato Times, 2 September 1993.

World Bank. 1991. Putting People First: Sociological Variables in Rural Development. Second Edition, edited by Michael M. Cemea. Published by Oxford University Press, p.11. 